\title{
Renewable Energy Policy and Market Developments in Kosovo
}

\author{
N. Avdiu ${ }^{1}$, A. Hamiti ${ }^{1}$ \\ ${ }^{1}$ Energy Regulatory Office of Kosovo \\ Address: St. Hamdi Mramori \#1, 10000 Prishtina, Republic of Kosovo \\ Phone/Fax number: +381 38 247-615 ext.126/+381 38 247-620, \\ e-mail: nysret.avdiu@ero-ks.org,ali.hamiti@ero-ks.org
}

\begin{abstract}
The paper highlights and analyzes the renewable energy policy instruments and market developments in Kosovo, with the aim of highlighting policy design and implementation lessons relevant to the wider and faster replication of RES (renewable energy sources) in Kosovo. The promotion of electricity from renewable energy sources is a high priority for several reasons. First of all the obligation rise from Kosovo's membership in the Energy Community Treaty of South East Europe, the security and diversification of energy supply, environmental protection and social and economic cohesion. RES-E (renewable energy sources - Electricity) penetration, support schemes and certificate of origin will be presented in the context of Kosovo energy market. Successful policies also take into account real market factors and barriers, the need for simplicity and accountability, minimum costs and profitability levels.
\end{abstract}

Key words - Renewable energy policy, support scheme, certificate of origin.

\section{Introduction}

During the 1990s, a deep transformation and restructuring in the electricity industry took place in many countries. The restructuring included privatization of state-owned enterprises, the separation of potentially competitive activities from natural monopoly activities, the creation of competitive wholesale and retail markets, and the application of performance-based regulatory mechanisms to the remaining regulated segments.

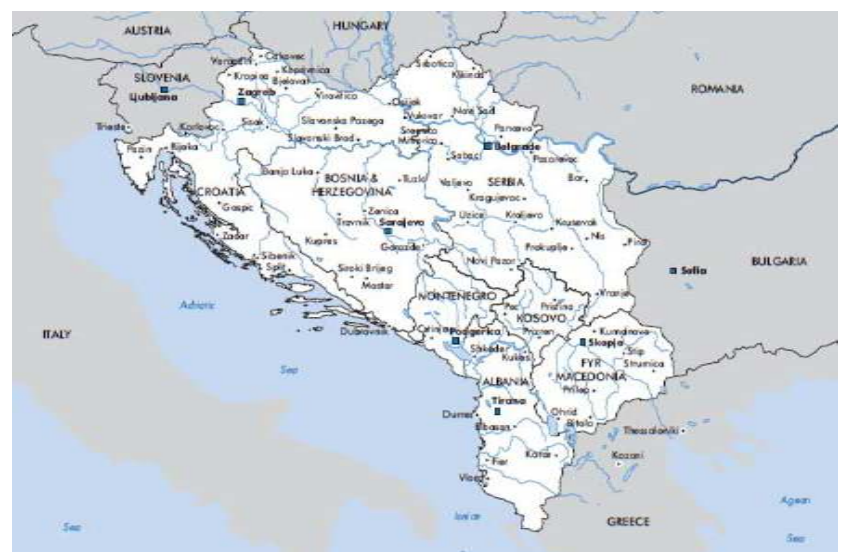

Fig. 1 Signatory parties of Energy Community Treaty of South East Europe: Albania, Bosnia and Herzegovina, Bulgaria, Croatia, Former Yugoslav Republic of Macedonia, Montenegro, Serbia, Romania, and Kosovo (as UNMIK).
The current electricity market in Kosovo is organizationally, technically and commercially recovering from the conflict of 1999. The Kosovo electric power system is in transition from vertical monopoly system to a market-driven commercial environment with well defined development goals agreed in the Energy Community Treaty of South East Europe (ECTSEE), [2]. The Kosovo today is an independent state located in South East Europe and is land-locked, a territory of $10,887 \mathrm{~km}^{2}$ and with a population estimated up to 2.1 million [8]. Since NATO (North Atlantic Treaty Organization) intervention in 1999, Kosovo was administrated by the United Nations under Security Council Resolution 1244 (United Nation Interim Administration Mission in Kosovo - UNMIK) up to 2008, when following the conclusions of the political process Kosovo has declared independence. Membership in the European Union (EU) is the goal of Kosovo's Government thus, the harmonization of its legislation with the European Union (EU).

\section{Electric Power Sector Development in Kosovo}

The structure of the Kosovo electricity sector is an important background variable for understanding the current stage of developments of RES-E. The Kosovo Parliament has adopted the Energy Strategy of Kosovo up to 2018, [10]. The primary legal and institutional framework for the restructuring and development of the Kosovo electricity market has been put into force [9]. The laws define who is responsible for various functions, which activities will be monopolies and which ones competitive as well as its regulation, etc. According to the primary lgislation, secondary legislation has been developed. The Ministry of Energy and Mine of Kosovo (MEM) was established in the beginning of 2005 and is responsible for the strategy and policy making for the energy sector. Energy Regulatory Office (ERO) is completely autonomous from any governmental department and exercises economic regulation in the energy sector with a key objective to "Set the Regulatory Framework for a transparent and non discriminatory energy market based on free market principles and promote competition". Stakeholders include: policy makers-parliament, goverment, sector regulator - ERO; electricity providers KEK (Korporata Energjetike e Kosovës) suppliers, 
generation and distribution, transmission operator and market operator; customers: large industrial and commercial customers, households; development partners and investors; civil society organizations including non-governmental organizations, labor unions, industry and business associations, and media; and oversight entities responsible for enforcing laws and regulations such as the ombudsman, judiciary, and audit offices. Currently the power sector of Kosovo is operated by the public owned electric enterprise called "Korporata Energjetike e Kosovës" Joint Stock Company (J.S.C.) and Kosovo Transmission System and Market Operator J.S.C. (KOSTT). Generation. Kosova has a substantial potential for electricity generation (lignite). The electric system of Kosovo is primarily supplied by two licensed KEK thermal power plants using lignite obtained from nearby mines: Kosovo A with an installed capacity of $800 \mathrm{MW}$ and Kosovo B with $678 \mathrm{MW}$, bringing it to total installed capacity of $1515.2 \mathrm{MW}$. Besides these plants, there are small hydro power plants with a total installed capacity of 43 MW. During the period 1989 - 1999, due to inadequate maintenance and political conflict, the reliability and the net output of the generating units and equipment has been seriously affected. Therefore, the actual available capacities are reduced to $970 \mathrm{MW}$, the peak demand during the winter period is more over $1100 \mathrm{MW}$.

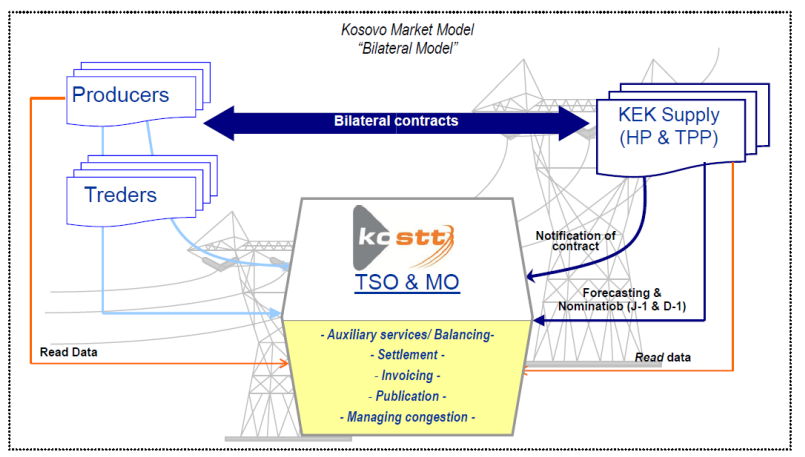

Fig. 2 Current Transitional market model in Kosovo

The KEK Distribution System Operator (DSO) is licensed by ERO and covers whole territory of Kosovo. The KEK also has the license for public supply and trade export-import and is responsible for all commercial activities including collection and customer services. Kosovo current market structure is transitional and presented in the Fig. 2. At present, while there are no legal restrictions on entry of new generators or suppliers, the Kosovo market effectively operates as a "single buyer model". Retail supply is dominated by public owned KEK, that include coal mines, generation, distribution. Administrative decisions issued by the Ministry of Energy and Mines permits all customers connected at $10 \mathrm{kV}$ and above to apply for a certificate of eligibility from ERO, allowing them to switch to an alternative supplier. By year 2015 by ECTSEE all customers should be eligible. Kosovo intends to introduce a bilateral contracting electricity market model accompanied by a balancing mechanism. However, the full market has yet to be implemented and instead an interim set of rules are used which do not apply imbalance charges and where bilateral contracts are not put in place. Access to the network. For the organization of the network access, Kosovo has chosen the regulated third party access system. Unbundling. The Kosovo transmission system is already independent from generation and distribution activities. The KEK licensees have already unbundled the accounts. The decision for legal unbundling of the Distribution Network from KEK Generation has been made in 2009 and this process will be completed in 2011, due to the process of privatization of DSO and Public Supplier. Electricity and the environment. The Ministry of the Environment and Spatial Planning holds the environmental responsibilities in Kosova. Kosovo is not member of any agreement relating to the climate change, but it is expected in future to manage $\mathrm{CO}_{2}$ and the gas emissions in general. As member of ECTSEE: each Contracting Party shall endeavor to implement the EU Directive's concerning pollution and emissions.

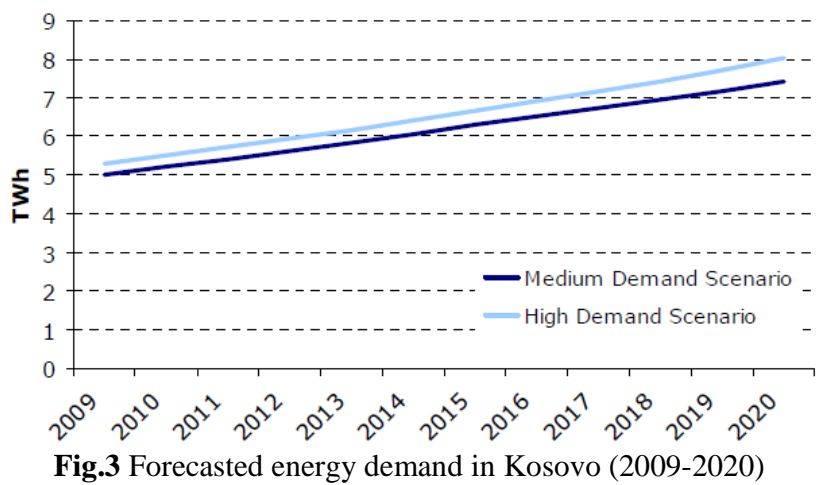

Supply-Demand: After the conflict of 1999 evolution of electrical energy production and consumption in Kosovo is closely linked to political events and to the resulting economic changes. The domestic generation, did not fulfill energy demand since 1999. As consequence the planned load shedding are carried out mainly when demanded consumption cannot be covered by domestic generation production and there is lack of import, or due to limitation of transmission network capacities. The lack of domestic electricity generation capacities has been covered by imports of energy, and by organized predetermined load shedding, according to respective schemes. Energy supply, actually electricity demand in Kosovo is covered by: three units of (lignite-based) "Kosovo A" Thermal Power Plant (TPP) and two units of "Kosovo B" TPP, having an overall capacity of 870 MW; "Ujmani" hydro power plant (HPP) with a capacity of $35 \mathrm{MW}$; and "Lumbardhi" HPP with a capacity of 8.3 MW.

\begin{tabular}{|c|c|c|c|c|c|c|c|c|c|c|c|c|}
\hline & 200 & 2010 & 2011 & 2012 & 2013 & 2014 & 2015 & 2016 & 2017 & 2018 & 2019 & 2020 \\
\hline TPP Kogove A & 13300 & 1.300 & 1.300 & 1.450 & 1.450 & 1.450 & 1.450 & 1.50 & 1.450 & 0 & 0 & 0 \\
\hline TPP Kosovo B & 3,300 & 3,300 & 3,300 & 3,300 & 2500 & 2,500 & 3,400 & 3.400 & 3440 & 3.400 & 3400 & 3400 \\
\hline IPP New Kosovo & 0 & 0 & 0 & 0 & 0 & 0 & 0 & 37750 & 7,500 & 11.250 & 14,892 & 14,922 \\
\hline 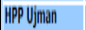 & 79 & 79 & 79 & 79 & 79 & 79 & 79 & 79 & 79 & 79 & 79 & 79 \\
\hline HPP h hui & 0 & 0 & 0 & 0 & 0 & 0 & 398 & 398 & 398 & 398 & 398 & 398 \\
\hline Trotal & 4.721 & 4.779 & 4,804 & 4.979 & 4.204 & 4.229 & 5.597 & 9.302 & 13,067 & 15.377 & 18,769 & 18,765 \\
\hline
\end{tabular}

Tab. 2 - Electricity Generation Forecast (GWh/yr)

The overall generation capacity is therefore slightly over $900 \mathrm{MW}$. The remaining electricity demand is met from imports. Import of electricity is relatively expensive, and certainly it will increase more in the near future due to significant lack of electricity in the region. The present importing/exporting capacity is $450 \mathrm{MW}$. Power generation forecasts for the period 2009-2018 have been 
prepared by MEM based on expected power generation from existing power plants, including continued operation of several units of "Kosovo A" TPP until 2017, "KosovoB" TPP, existing HPP and new ones planned to be built, "New Kosovo" TPP with 2x300 MW. Domestic electricity supply is envisaged to evolve as follows: Power generation from Kosovo A TPP, operating with A3, A4 and A5 units, and this requires investments for maintenance and overhauls, thus enabling these units to operate until the end of 2017, when they will be decommissioned; Power generation from Kosovo B TPP, operating with B1 and B2 units, (it is anticipated that these two units will be rehabilitated during the period 2013 2014, this will include investments required to meet emission standards under the EU Directive on Large Combustion Plants), and will continue their commercial operation until 2027 - 2030; Power generation from existing "Ujmani" HPP which, with maintenance and rehabilitation, could continue its commercial operations for a long-term period. - Power generation from the small "Lumbardhi" HPP; Power generation from the new"Zhur" HPP, projected to be constructed by 2014 and to begin its commercial operation by 2015; Power generation from the "New Kosovo" TPP. Its first generation unit is expected to enter into operation in 2016 and the last one by 2019. Based on the above assumptions, electricity generation from domestic power plants for period 2009-2018 is shown in Tab. 2.

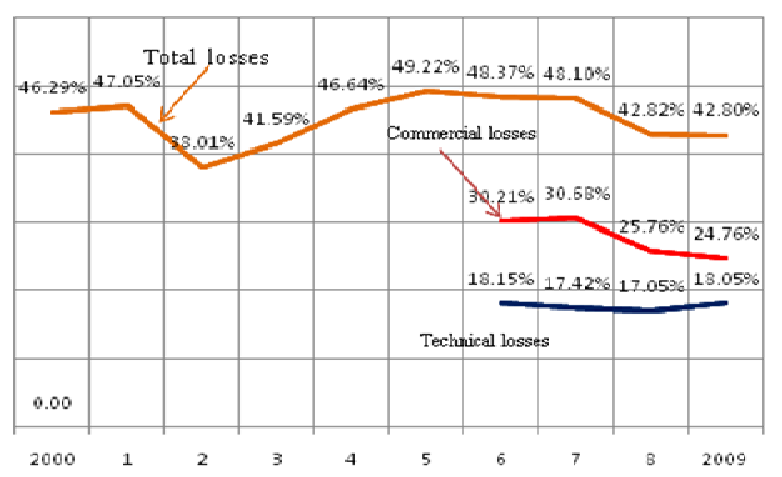

Fig. 3 Losses in distribution network, technical losses and commercial

Network losses. Theft of electricity after the conflict is still present and has detrimental effect on the day-to-day operations of a KEK, along with high technical and commercial losses, are major problems in electricity sector in Kosovo and this has the direct impact to the economy. Actually KEK is not in position to collect all billed electricity. Sector planning. In a competitive electricity sector, market signals and projections of demand and supply guide the investment plans of electricity utilities. Planning is crucial for the utilities' continuing profitability and viability. Licenses in Kosovo are obliged to submit short and long term planning to ERO for approving. Sector financial management. The actors of Kosovo electricity market are expressing weaknesses in the financial management system with having direct influence in viability and sustainability of the sector. Setting electricity prices at levels that ensure cost recovery and promote efficiency, strengthening the collection of payments, and enforcing accountability for performance are crucial for future development of Kosovo electricity sector. In Kosovo however, setting appropriate price levels may be difficult due to affordability of population and weak institutions. Procurement in the sector includes: import of electrical energy, equipment and spare parts for power generation plants, transmission and distribution facilities; supply of oil, electric meters, cables, and other items; vehicles and equipment; and services. Procurement in Kosovo is subject to the public procurement laws requirements and donors' requirement. Privatization of utilities and new generation investments. The critical issue for Kosovo today is security of supply. The "Kosovo Energy Strategy 20092018" [10], sets the goals for developing a sustainable energy sector, which includes also involvement of private investments in generation and mining and privatization of the distribution network. There is a process of tendering for construction of new TPP $2 \times 300 \mathrm{MW}$, called "New Kosovo", privization of existing TPP Kosovo B, and of Distribution and Supply businesses.

The market environment, within which renewable energy deployment in Kosovo takes place, contains many uncertainties, since the new coal generation investment most probably will be under long power purchase agreement and some type of single buyer market design. The effects of privatization and commercialization on renewable energy are difficult to judge. The environmental effects of privatization can be positive or negative, depending on such factors as the strength of the regulatory body and the political and environmental policy situation in a country and affordability of customers. Private utilities are more likely to focus more on costs and less on public benefits, unless specific public mandates exist. On the positive side, privatization may promote capital-intensive renewable energy by providing a new source of finance-capital from private debt and equity markets.

\section{RES and its Policy Context}

Kosovo has substantial potentials for expanding the use of renewable energy sources in electricity generation. Based on the currently available data and our estimates, the medium-term potential may support, by 2020, RES generation in the level of $2.5 \mathrm{TWh}$ per year.

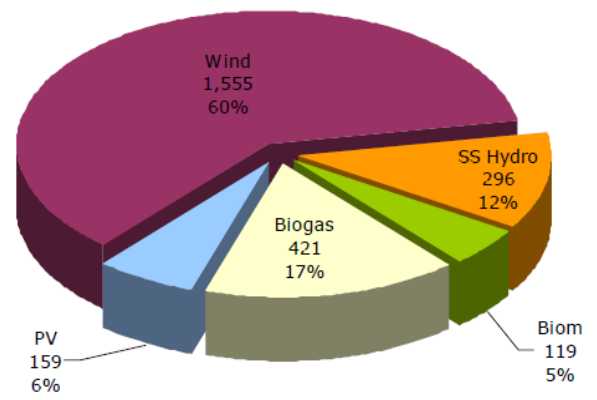

Fig.4 RES-E Medium-term Incremental Potential (GWh; \%)

Other energy potentials are as follow: Solar energy The total annual radiation in Kosovo varies between 1,100 and 1,250 kWh/m2/year. Biomass - various types of biomass are available in Kosovo. The major contribution to the biomass resource is from wood; additional contribution comes from livestock waste and 
agricultural waste. Agriculture biomass in the form of straw is produced in many municipalities by a large number of small farmers. Solid waste - a preliminary assessment of the solid waste resources indicates that limited contribution to energy generation can be expected. Wind power - the present available wind data for Kosovo do not indicate that sufficient wind energy resources are available in Kosovo for viable utilization. Geothermal energy - the results from surveys of available boreholes indicate low water and soil temperatures. The temperatures are lower than required for heating purposes and electricity generation. However, the present boreholes are only few hundred meters deep; temperature measurements in boreholes of 2-3 km depth may give a better basis for evaluating the available potentials for geothermal energy resources in Kosovo. By 2010 Kosovo has around 3\% of total energy production from renewable energy, consisting mainly of hydro and wind power.

By early 2010, policy for renewable energy at the national level existed in at least 85 countries worldwide, including all 27 European Union member states. In 2008, all 27 EU countries confirmed national targets for 2020 , following a 2007 EU-wide target of 20 percent of final energy by 2020 , but more than two-thirds of the thouse countries with existing national targets were aiming for 2020 or beyond in some manner, [6].

\begin{tabular}{|c|r|r|r|r|r|r|r|r|r|r|r|}
\hline \multirow{2}{*}{$\begin{array}{c}\text { Source of } \\
\text { Energy }\end{array}$} & \multicolumn{8}{|c|}{ Indicative targets for RES electicity consumption (GWh) } & Extrapolation \\
\cline { 2 - 12 } & $\mathbf{2 0 0 7}$ & $\mathbf{2 0 0 8}$ & $\mathbf{2 0 0 9}$ & 2010 & $\mathbf{2 0 1 1}$ & $\mathbf{2 0 1 2}$ & $\mathbf{2 0 1 3}$ & $\mathbf{2 0 1 4}$ & $\mathbf{2 0 1 5}$ & $\mathbf{2 0 1 6}$ & \multicolumn{2}{|c|}{$\mathbf{2 0 2 0}$} \\
\hline Hydro & 125,8 & 134,6 & 145,0 & 156,3 & 167,0 & 178,4 & 190,5 & 203,2 & 216,7 & 230,4 & 302,1 \\
\hline Wind & 0,0 & 0,0 & 0,0 & 32,6 & 68,7 & 108,5 & 151,9 & 199,8 & 252,1 & 309,9 & 652,1 \\
\hline Solar & 0,0 & 0,0 & 0,0 & 0,0 & 0,0 & 0,0 & 0,0 & 0,0 & 0,0 & 0,0 & 0,0 \\
\hline Biomass & 0,0 & 0,0 & 0,0 & 0,0 & 11,6 & 17,5 & 19,8 & 23,3 & 29,1 & 29,1 & 38,4 \\
\hline Total & 125,8 & 134,6 & 145,0 & 188,9 & 247,4 & 304,4 & 362,2 & 426,2 & 497,9 & 569,4 & 992,5 \\
\hline
\end{tabular}

Tab. 3 Indicative targets for electricity consumption produced from RES (GWh).

To fulfil the mandate contained in the Law on Energy, in 2007, the Kosovo Government set indicative targets for consumption of electrical energy and heating from renewable sources and cogeneration, Tab.3. If extrapolated to 2020, they would envisage RES-E production to reach $1 \mathrm{TWh}$. In the study [5] targets for renewable energy by 2020 have been calculated for each of the seven Contracting Parties of ECTSEE, as set out in the new Renewable Energy Directive 2009/28/EC. Kosovo in total has $33.9 \%$ energy consumption from RES. The calculation of the 2020 target involves three elements: share of renewable energy, base year 2005, flat-rate increase, additional residual effort determined on the basis of relative GDP per capita, but the study has highlighted considerable problems with availability of reliable data related to the biomass consumption statistics including inconsistent data collection and measurement methods across. Good national policies can support renewable energy development by driving markets, providing certainty in the investment market, and incorporating the external benefits of the technologies into cost/benefit calculations. Kosovo is committed to comply with RES directives requirements listed by ECTSEE and in conformity with the above, have harmonised the primary and secondary legislation on RES [9].
Energy Strategy of the Republic of Kosovo [10], pays special attention to compliance with European Union Acquis, the provisions of which are compulsory for Kosovo, as it has taken over these responsibilities through its membership to the Energy Community Treaty. The Strategy aims to stimulate rational use of energy and increased energy efficiency as well as utilization of renewable energy resources and introduction of new technologies for implementing the environmental standards as set forth by law.

The various responsibilities and duties on RES per key stakeholder are:

-MEM develops the Strategy Implementation Programme which defines programs for incentives for the investment in RES; prepares Implementation Programmes to promote RES, proposals for incentives and secondary legislation, after consulting the Energy Regulatory Office; each year establishes Indicative Targets for the consumption of electricity or heat generated from RES or cogeneration;

- Energy Regulatory Office: Approves standard rules on costs for grid connections, in consistency with the Energy Strategy, based on objective, transparent and nondiscriminatory criteria, taking particular account of all the costs and benefits associated with the connection of these producers to the system, in setting tariffs, provide sources of funding through tariffs, implemented by TSO, operating under transparent procedures; entitled to grant certificates of origin to energy enterprises that generate electricity using RES or waste and co-generators that produce electricity and heat in a single plant; Through tariff methodology will encourage interruptible rates, load balancing rates and other mechanisms to improve energy efficiency and demand side management, including consideration of the development of RES.

- TSO dispatching generation, gives priority to generation using RES as permitted under the Grid Code and other applicable rules and regulations.

- TSO/DSO establishes and publishes standard rules on who bears the costs of technical adoptations, such as grid connections and grid reinforcements, necessary to integrate new generators feeding electricity produced from RES into the interconnected system. Such shall be aproved by ERO; Provide any new generator wishing to be connected with a comprehensive and detailed estimate of the costs associated with the connection.

- Supplier gives purchasing priority to electricity for which a certificate of origin has been issued, required to purchase at a regulated price the entire amount of electricity for which a certificate of origin has been issued and are part of support fund to meet the needs of electricity consumption in Kosovo. The contrcating of RES is based on long Power Purchase Agreement.

\section{RES-E Support Mechanisms}

Today in the world a great number of countries, developed and transition countries, have some type of policy to promote renewable power generation [6]. In assessing different schemes for RES-E promotion and their suitability for implementation in Kosovo [1], the following criteria are relevant: - the legal requirements; - 
the relative performance of the different types of instruments, both from a theoretical point of view and in practice;- the specific circumstances of Kosovo. In terms of the legal requirements, the provision in the Kosovo Law on Electricity suggests the use of a feed-in tariff scheme, and use the Certificate of Origin $(\mathrm{CoO})$ as part of the scheme. In fact, the international experience suggests that feed-in tariffs are particularly effective in promoting the use of renewable energy in electricity generation. Investors like feed-in tariffs because they provide certainty on the revenue stream from the sale of electricity produced from renewable.

The present analysis of RES-E in Kosovo is based on an incremental approach [1], and for that reason identification of the incremental supply is needed, meaning the net increases in conventional generation above the existing levels from 2008. Tab. 2 shows that the "incremental conventional generation" in 2020 is $13.840 \mathrm{GWh} /$ year. In addition, it is important to point out that if any of the planned conventional units does not enter into operation before 2020 and additional energy is needed to fulfill forecasted demand, then imports will provide the energy to fill the gap. Therefore, the imports as a source of power supply cannot be disregard. In basic economic theory, one prerequisite for economic efficiency is that the marginal benefit of any given activity equals its marginal cost. This would require that the marginal social benefit attributed to the consumption of, say, one $\mathrm{kWh}$ of electricity, is exactly offset by the marginal social cost of generating this $\mathrm{kWh}$. When analyzing policies to promote RES-E, the main concern is how to allocate electricity generation amongst available technologies, such as RES and conventional sources of energy. In this respect, economic efficiency would require that marginal social generation costs are equalized across the different sources. This is known as the principle of 'equi-marginality' in economic theory [1]. While defining economic efficiency one need to bear in mind the difference between static efficiency and dynamic efficiency. Static efficiency implies that no other allocation of generation capacity amongst different RES-E will yield a lower overall cost of providing a given share of RES-E. All it takes to achieve this static efficiency is a uniform price which will then provide different RES-E technology specific penetration. Here the main focus is on potentials and costs of RES-E in Kosovo and therefore on the level of support required to promote their development.

The analysis presented for assessing the requirements and impact of promoting RES-E in Kosovo is based on: General assumptions (target year, static or dynamic efficiency considered, incremental or total modeling, etc.); Social and private supply curves (given costs or probabilistic approach, potential estimation by RES class, discount rate, monetization of externalities, etc.); and Demand side perspectives (energy efficiency, demand forecasting, etc.). Net electricity demand in Kosovo reached 4.45 TWh in 2008. According to existing estimations, future net electricity demand may increase up to 7-7.4 TWh in 2018. In order to obtain medium-term values, we have extrapolated those values and obtained a forecasted demand in 2020 at 7.4-8 TWh, as shown in Fig.3. For the purpose of the present analysis, we have employed an "incremental" approach and made reference to the medium demand growth scenario. Therefore, incremental demand in Kosovo in 2020 is approximately $3 \mathrm{TWh}$ and, if we assume an additional $10 \%$ for transmission losses, gross incremental demand in 2020 becomes 3.3 TWh. The supply curve for each RES-E technology is based on the medium-term potential - not all the theoretical potential - and on the actual costs for the different technologies. Also, this medium-term potential does not cover more that $20 \%$ of total demand. Another issue that is important to point out is that Kosovo has no accurate estimation of potentials for any RES technology.

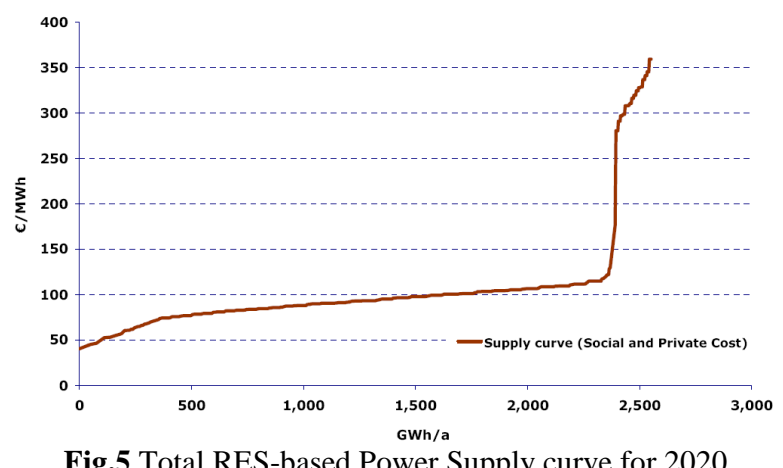

Fig.5 Total RES-based Power Supply curve for 2020

The combined RES-E supply curve for 2020 is obtained by adding up the supply curves for the different technologies, separately for RES-E from small hydro, wind, solar PV, biogas and biomass, describing the way in which the supply curves have been constructed, including resource-specific estimated medium-term potentials and economic merit order. The total incremental RES-E supply curve for Kosovo in 2020 is illustrated in Fig.5.

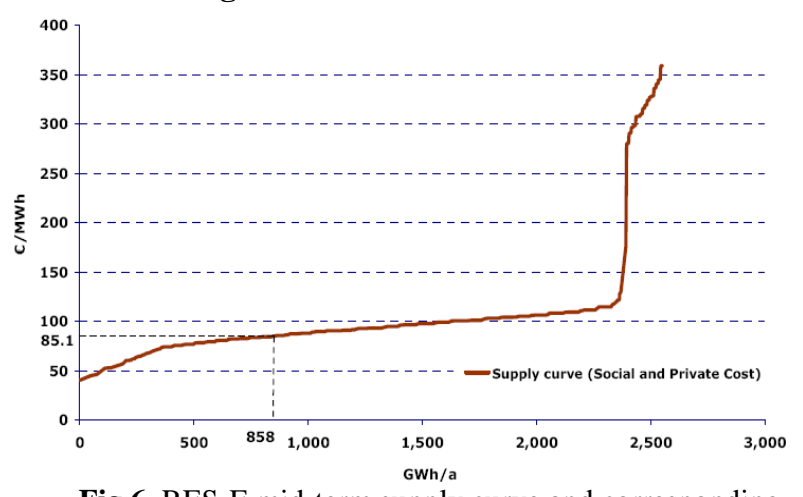

Fig.6 RES-E mid-term supply curve and corresponding single FIT

According to analysis, the total medium-term potential for RES-based on-grid power generation in Kosovo is around $2,550 \mathrm{GWh} /$ year. The supply curve is relatively elastic, from $75 € / \mathrm{MWh}$ to $120 € / \mathrm{MWh}$ up to 2,330 $\mathrm{GWh}$, and then becomes extremely steep because of the high cost of some technologies such as solar and biomass. The targets defined by MEM may be achieved in at least two different ways: - one possibility is to set a single feed-in tariff common to all RES-E technologies. This tariff will allow the overall RES-E target to be achieved, but it may not deliver the technology-specific targets; the other possibility is to set multiple feed-in tariffs with the objective of achieving each technologyspecific target and therefore the whole RES-E target as well. Fig.8 shows the RES-E supply curve and the tariff 
that allows achieving the total RESE indicative target. The Figure indicates that a single feed-in tariff of $€ 85.14 / \mathrm{MWh}$ corresponds to the incremental RES-E penetration target. The resulting technology penetration mix based on this single feed-in tariff level is illustrated in Fig.7.

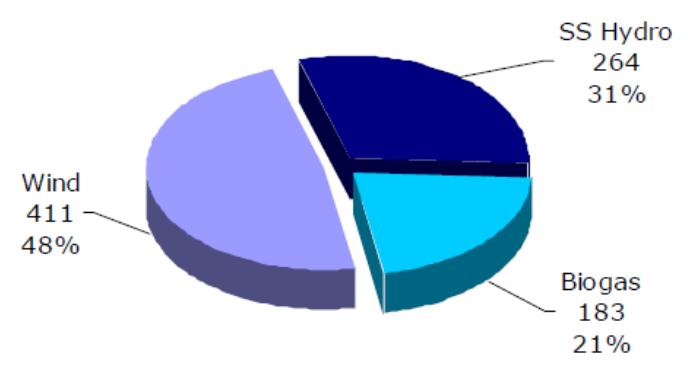

Fig.7: Technology-specific Penetration under Single FIT (GWh/year; \%)

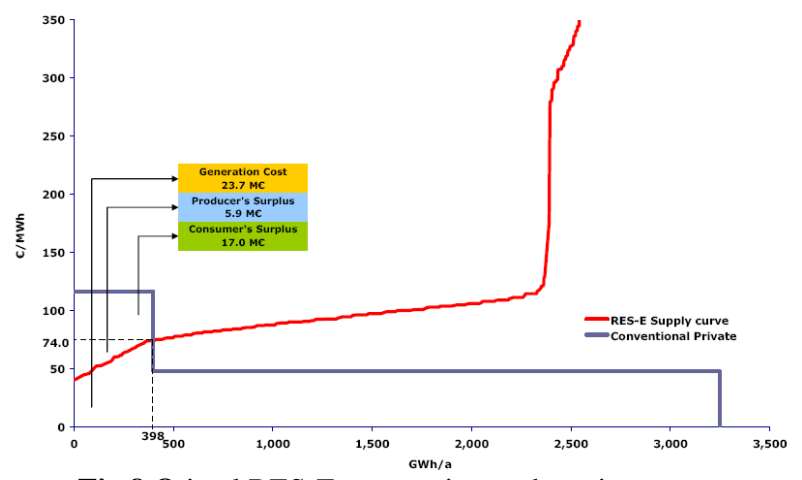

Fig.8 Otimal RES-E penetration under private costs

Support Scheme and Certificate of Origin. ERO has adopted the Rule for Support Scheme based on provisions of Kosovo Laws with main objectives: to promote the development of electricity generation capacity using renewable energy sources in a transparent manner; to attract domestic and international investors by providing a conducive environment for investing in generation capacity using renewable energy; to support, or at least not hinder, the development of a competitive electricity market, in Kosovo or regionally, when the conditions of the electricity sector(s) allows it; to be compatible with Kosovo participation in "Joint Projects" with EU Member States, as envisaged in Article 9 of Directive 2009/28/EC; to be simple and cost-effective to implement. Also have been adopted the Rule for the issuing and usage of $\mathrm{CoO}$ in respect to electricity produced from RES-E, waste and in Cogeneration Heat Plants.

The Support Scheme described above is shown graphically in Fig. 9.

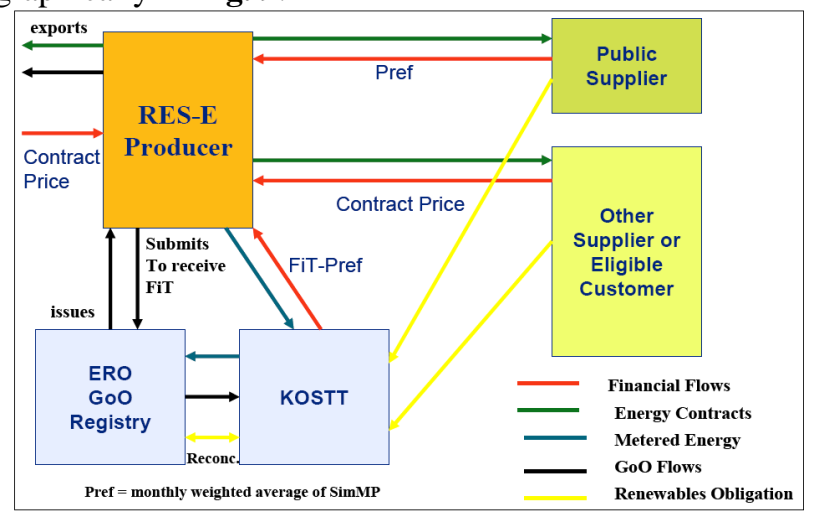

Fig.9 Kosovo "hybrid" Feed in Tariff/CoO Scheme

\section{Conclusion}

The paper presents the renewable energy policy instruments and market developments in Kosova. The promotion of electricity from renewable energy sources is a high priority for several reasons, first of all obligation rise from membership of Energy Community Treaty of South East Europe, the security and diversification of energy supply, environmental protection and social and economic cohesion and obligation. RES-E penetration, support schemes and certificate of origin are presented in context of Kosovo energy market. Successful policies also take into account real market factors and barriers.

\section{References}

[1] Kosovo-Regulatory framework for RES procedures and methodology for RES electricity pricing, "Merkados", ERO 2009 Prishtina Kosovo; (www.ero-ks.org).

[2] Treaty establishing the Energy Community, Athens 2005 (www.energy.community.org)

[3] Eichhammer, R.H.W., et al., 'How to promote renewable energy systems successfully and effectively ', Energy Policy, Volume 32, Issue 6, April 2004, pp. 833 - 839. .

[4] Johansson T.B. and Turkenburg W., 'Policies for renewable energy in the European Union and its member states: an overview', Energy for Sustainable Development Vol. VIII No. 1, March 2004

[5] Study on the Implementation of the New EU Renewable Directive in the Energy Community- 2020; Energy Community Secretariat Vienna 2010 (www.energy.community.org);

[6] Project: PROGRESS Promotion and growth of renewable energy sources and systems, European Commission, DG Energy and Transport, under contract no. TREN/D1/422005/S07.56988, Utrecht, 5 March 2008

[7] Renewable Global Status Report, (http://www.ren21.net);

[8] Country Profile: Kosovo (http://www.euclidnetwork.eu)

[9] The -Law on Energy 2004/8, law on Electricity 2004/10 Law on the Energy Regulator 2004/9; all laws have been amendmented on 2010 (http://www.assemblyKosovo.org)

[10] Energy Strategy of the Republic of Kosovo 2009-2018 http://www.assembly-Kosovo.org.

\section{Acknowledgement}

The financial supports of the Energy Regulatory Office of Republic of Kosovo are highly acknowledged. 